\title{
PRIORIZAÇÃO DA ÁGUA DE REUSO EM BACIAS HIDROGRÁFICAS COM BASE NO PLANEJAMENTO DE RECURSOS HÍDRICOS: PROPOSTA METODOLÓGICA E EXEMPLOS DAS BACIAS DO RIO GRANDE E DO PIANCÓ-PIRANHAS-AÇU
}

\author{
WATER REUSE PRIORITIZING IN HYDROGRAPHIC BASINS BASED ON WATER \\ RESOURCES PLANNING: METHODOLOGICAL PROPOSAL AND EXAMPLES OF GRANDE \\ AND PIANCÓ-PIRANHAS-AÇU RIVER BASINS
}

\author{
Sérgio Rodrigues Ayrimoraes Soares ${ }^{a}$, Ana Sílvia Pereira Santos ${ }^{b}$ \\ ${ }^{a}$ Agência Nacional de Águas e Saneamento Básico, ${ }^{b}$ Universidade do Estado do Rio de Janeiro
}

ssoares@ana.gov.br, ana.pereira@uerj.br

Submissão: 19 de março de 2021 Aceitação: 1 de julho de 2021

\section{Resumo}

O reuso de água é uma importante alternativa tanto para a disposição final de efluentes do tratamento de esgotos, como para a diversidade da matriz hídrica, especialmente em regiões de escassez. Assim, no contexto da gestão de recursos hídricos e saneamento, a prática de reuso pode ser vista como solução, especialmente, em duas situações: no caso de áreas que sofrem com a falta de água por questões climáticas, como a região do Semiárido; e no caso de regiões onde seus corpos d'água apresentam dificuldades de manterem os requisitos de qualidade da água, quando do recebimento de efluentes, mesmo que tratados. Como ferramenta de planejamento, o presente trabalho apresenta uma metodologia de priorização da aplicação do reuso de água (PARBH) nessas áreas em três etapas: (a) classificação dos municípios a partir da complexidade do tratamento de esgotos requerido; (b) mapeamento das áreas irrigadas (atuais e potenciais) e de demandas de água para agricultura irrigada; e (c) integração dos dados em uma bacia hidrográfica, no âmbito da elaboração dos planos de bacia. Foram analisados os casos das bacias hidrográficas do rio Grande e dos rios Piancó-Piranhas-Açu que, em diferentes contextos, possuem uma estratégia comum de aprimoramento dos estudos para a definição da viabilização do reuso (modelo de negócio). Por fim, ressalta-se que a sistematização do reuso de água no Brasil ainda demanda grandes esforços para transpor os diversos desafios que se apresentam, tais como baixos índices de coleta e tratamento de esgotos, desempenhos operacionais insatisfatórios, falta de regulamentação, falta de estudos técnico-científicos, cultura histórica de falsa abundância de água, entraves burocráticos, e a questão da rejeição psicológica natural em relação à água de reuso.

Palavras-chave: plano de bacia hidrográfica; reuso de água; destinação de efluentes tratados; agricultura irrigada; escassez hídrica.

\section{Abstract}

Water reuse is an important alternative both for treated wastewater final disposal and for the diversity of the water matrix, especially in regions of scarcity. Thus, in the context of water resources management and sanitation, the practice of reuse be a solution, especially in two situations: areas that suffer from lack of water due to climatic issues, such as the Semi-arid region; and regions where their water bodies cannot maintain their framing levels, when receiving wastewater, even treated. As a planning tool, the present work presents a methodology for prioritizing the application of water reuse in these areas in three stages: (a) classification of municipalities based on the complexity of the required wastewater treatment; (b) mapping of irrigated areas (current and potential) and water demands for irrigated agriculture; and (c) integration of the data in a hydrographic basin, within the scope of the elaboration of the basin plans. The cases of Grande and the 
Piancó-Piranhas-Açu river basins were analyzed, which, in different context, have a common strategy for improving the studies to define the viability of water reuse (business model). Finally, it is emphasized that the water reuse systematization in Brazil still requires great efforts to overcome the various challenges that arise, such as low rates of sewage collection and treatment, unsatisfactory operational performance, lack of regulation, lack of technical-scientific studies, historical culture of false water abundance, bureaucratic obstacles, and the issue of natural psychological rejection in relation to water reuse.

Keywords: water basin planning; water reuse; treated wastewater disposal; irrigated agricultural; water scarcity.

\section{INTRODUÇÃO}

Em julho de 2010, a Organização das Nações Unidas (ONU) declarou que o acesso à água limpa e segura e ao saneamento básico são direitos humanos fundamentais (UNITED NATIONS, 2010). Posteriormente, em 2015, a ONU estabeleceu os Objetivos do Desenvolvimento Sustentável (ODS), cujo Objetivo 6 (ODS6) é assegurar a universalidade da disponibilidade e gestão sustentável da água e do saneamento. Este, por sua vez, está dividido em metas a serem cumpridas até o ano 2030, em que duas delas se referem ao direito humano à água $e$ ao saneamento: \#6.1 - Alcançar o acesso universal e equitativo à água potável e segura para todos; \#6.2 - Alcançar o acesso ao saneamento e à higiene adequados e equitativos para todos, e acabar com a defecação a céu aberto, com especial atenção para as necessidades das mulheres e meninas e daqueles em situação de vulnerabilidade. (UNITED NATIONS, 2015). O ODS6 inova ao tratar de saneamento e recursos hídricos em uma perspectiva integrada (ANA, 2019a), incluindo, por exemplo, metas de melhoria de qualidade da água (\#6.3) e de eficiência do uso da água (\#6.4), visando reduzir substancialmente o número de pessoas que sofrem com a escassez.

De fato, atualmente, muitas são as incertezas em relação à disponibilidade hídrica no mundo e, particularmente, no Brasil, em função do crescimento populacional e do consequente aumento da demanda hídrica para abastecimento doméstico e produção de bens de consumo, além das alterações climáticas. Apesar de o Brasil possuir uma grande quantidade de água em seu território, a sua distribuição é desigual em relação à densidade populacional (ANA, 2017a). Incorpora-se a esse cenário, a acentuada poluição hídrica decorrente dos baixos índices de cobertura com serviços de esgotamento sanitário e a cultura da falsa abundância de água, que incentiva o seu desperdício e limita o seu uso racional. De acordo com ANA (2017b) somente 53\% do esgoto gerado no Brasil é coletado e $45 \%$ é tratado; em relação ao esgoto coletado, $75 \%$ é tratado. No mundo, estima-se que $52 \%$ do esgoto coletado seja tratado, com forte participação dos países com mais baixo desenvolvimento socioeconômico nesse valor reduzido (JONES et al., 2021).

O Índice de Segurança Hídrica - ISH, desenvolvido no âmbito do Plano Nacional de Segurança Hídrica (ANA, 2019b), faz uma composição de indicadores que incorporam a dimensão humana (abastecimento de água para população) e ambiental (poluição hídrica) já citadas, além das dimensões econômicas (oferta de água para o setor produtivo) e de resiliência, que leva em conta o potencial dos estoques de água e as questões climáticas. O resultado do ISH para o Brasil possibilitou identificar as áreas mais críticas e vulneráveis com relação a segurança hídrica, conforme indicado na Figura 1.

$\mathrm{Na}$ análise da Figura 1, duas situações merecem destaque em se tratando de baixa segurança hídrica. A primeira delas refere-se à região do Semiárido, que abrange os estados da região nordeste (Alagoas, Bahia, Ceará, Paraíba, Pernambuco, Piauí, Rio Grande do Norte e Sergipe), além do norte do estado de Minas Gerais, onde a seca se faz presente ao longo de toda a sua história, levando essa região a um dos mais baixos índices de desenvolvimentos socioeconômicos do país (LIMA et al., 2020). A segunda, refere-se às áreas mais populosas do país, nomeadamente as regiões geográficas Sudeste e Sul, onde o consumo de água é elevado e a disponibilidade dos corpos hídricos para atendimento das demandas é limitada, além de apresentarem elevados níveis de poluição hídrica. Para essas situações, o Plano Nacional de Segurança Hídrica (PNSH) preconiza o reuso de água como prática que deve ser considerada nos estudos de aproveitamento de recursos hídricos, como alternativa complementar para lidar com a escassez hídrica.

O reuso de água vem se destacando como uma importante fonte alternativa para incremento 
do portfólio hídrico regional, no sentido de apresentar outra fonte de água além das tradicionais, para diferentes demandas, para 0 planejamento da gestão de recursos hídricos e para a solução de conflitos pelo uso da água (ANGELAKIS et al., 2018; MUKHERJEE e
JENSEN, 2020). No mundo, estima-se que o índice de reuso de água em relação ao esgoto tratado seja de $11 \%$ (JONES et al., 2021), enquanto no Brasil, Santos e Vieira (2020) estimaram que esse índice é de 1,5\%.

\section{Figura 1: Representação da criticidade e da vulnerabilidade regionais no Brasil em função do Índice de Segurança Hídrica}

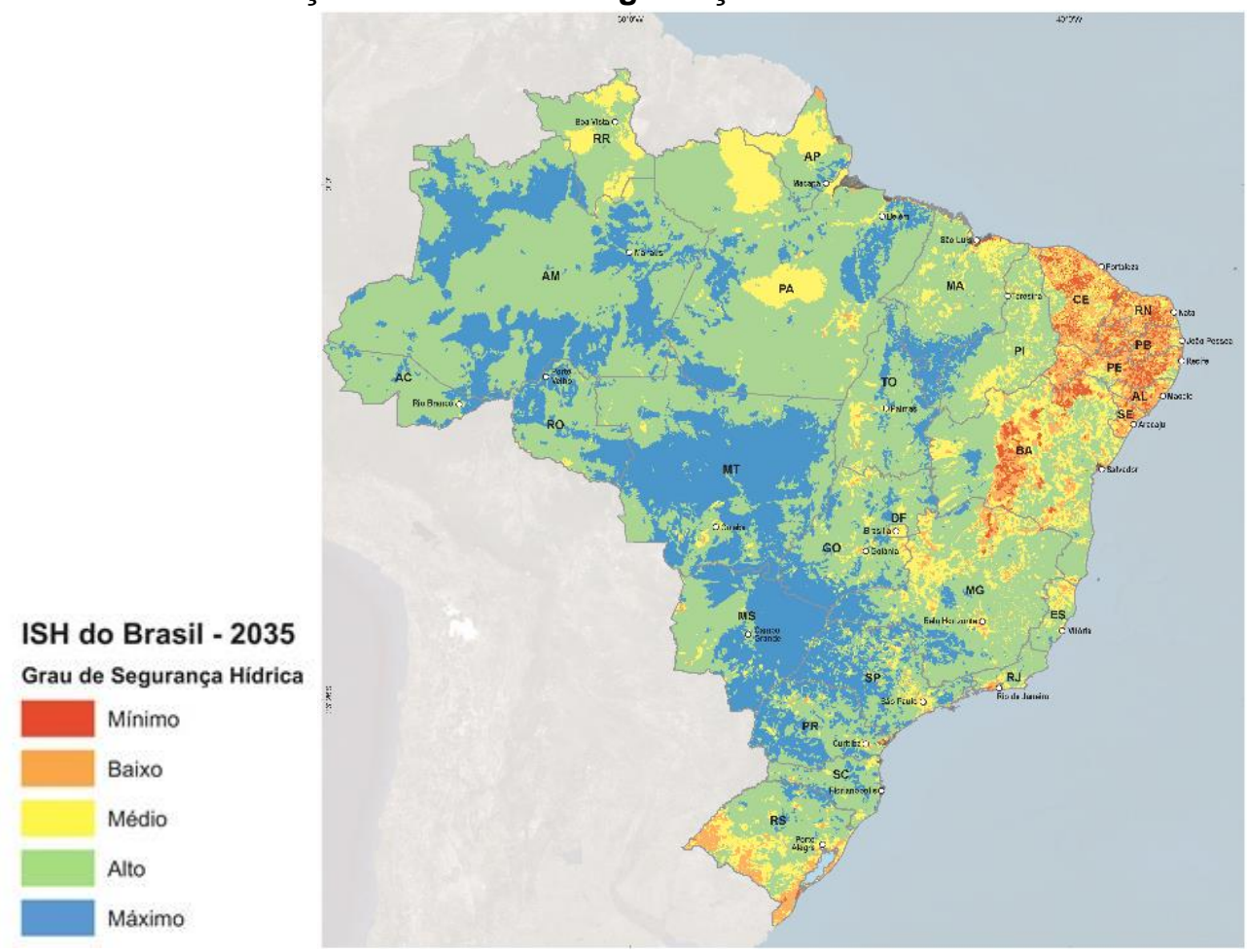

Fonte: ANA (2019b).

De forma a colaborar com os estudos de planejamento econômico para o mundo no período pós COVID-19, a Water Europe destaca que a água será o principal fator de relançamento da economia, ressaltando a sua reutilização como um dos principais elementos para o aumento da disponibilidade hídrica na Europa e em todo o mundo (WE, 2020).

No Brasil, dois cenários relevantes que merecem destaque quando se trata da inclusão sistêmica da água de reuso no planejamento de recursos hídricos e saneamento são: i) a escassez crônica de água que acomete principalmente os municípios inseridos na região do Semiárido e a consequente ausência de corpos receptores para a diluição de efluentes; e ii) a incapacidade de recebimento de cargas orgânicas remanescentes nos corpos hídricos em regiões com disponibilidade hídrica satisfatória, em função dos elevados índices de poluição hídrica. Os municípios do país com essas duas realidades encontram-se identificados no Atlas Esgotos (ANA, 2017b).

Adicionalmente, uma etapa importante em um projeto de reuso de água se refere à sua aplicação. $O$ reuso voltado para atividades agrícolas vem ganhando destaque em diversas partes do mundo, visto que aumenta a disponibilidade de água bruta nos corpos hídricos (HESPANHOL, 2008; ANGELAKIS et al., 2018), possibilita uma fonte de fertilizante (HORTEGAL FILHA et al., 2018), e geralmente apresenta menor custo de tratamento do que a água potável (LAHNSTEINER et al., 2018). Em escala nacional, o Atlas Irrigação (ANA, 2017c; ANA, 2021) apresenta um panorama da agricultura irrigada em todo o território brasileiro, a partir do mapeamento das áreas irrigadas $\mathrm{e}$ estimativa das demandas hídricas.

Os Atlas Esgotos e Irrigação são pontos de partida, mas para maior efetividade do 
planejamento, é importante que a estratégia para o reuso da água seja avaliada e detalhada no âmbito de cada bacia hidrográfica. Nesse contexto, os planos de bacias, instrumentos de gestão previstos na Política Nacional de Recursos Hídricos - Lei 9433/1997 (BRASIL, 1997), são o espaço ideal para esse desenvolvimento. Os planos de bacia são documentos que, a partir de uma base técnica, definem a agenda programática de gestão da água, dentro de uma perspectiva de usos múltiplos e com o envolvimento de órgãos governamentais, sociedade civil e setores usuários (SOARES et al., 2019).

Nesse sentido, o objetivo do presente trabalho é apresentar uma metodologia que utilize a base técnica do Atlas Esgotos e do Atlas Irrigação e de planos de recursos hídricos, para facilitar a Priorização da Água de Reuso em Bacias Hidrográficas (PARBH). Como exemplos da aplicação, são avaliados os casos das Bacias Hidrográficas do rio Grande (MG/SP) e do rio Piancó-Piranhas-Açu (PB/RN), que tiveram seus planos de bacia implementados em 2017 e 2016, respectivamente, e que possuem diferentes realidades do ponto de vista do balanço hídrico, da situação dos sistemas de esgotamento sanitário e do tipo de agricultura irrigada.

\section{METODOLOGIA}

A metodologia do presente trabalho (Figura 2) tem por base a utilização dos dados apresentados no Atlas Esgotos - Despoluição de Bacias Hidrográficas (AE) (ANA, 2017b) e no Atlas Irrigação - Uso da Água na Agricultura Irrigada (AI) (ANA, 2017c; ANA, 2021), além do detalhamento em planos de recursos hídricos como estratégia para priorização e viabilização das ações de reuso em bacias hidrográficas. O processo de discussão dos dados estabelece roteiro, cuja aplicação é exemplificada a partir dos casos do Plano Integrado de Recursos Hídricos da Bacia do Rio Grande (PIRH Grande) e do Plano de Recursos Hídricos da Bacia dos rios Piancó-Piranhas-Açu (PRH-PPA).

Basicamente, a metodologia PARBH consiste em três etapas complementares: (a) classificação dos municípios a partir da complexidade do tratamento de esgotos requerido com base nas modalidades definidas no $\mathrm{AE}$; (b) mapeamento das áreas irrigadas (atuais e potenciais) e de demandas de água para agricultura irrigada, a partir dos dados apresentados no Al; e (c) integração dos dados em uma bacia hidrográfica, no âmbito da elaboração dos planos de bacia.

De maneira geral, na etapa a, tem-se o objetivo de definir o universo de municípios que devem tratar, prioritariamente, o reuso de água como alternativa para a destinação final dos efluentes tratados. $\mathrm{Na}$ etapa $\mathbf{b}$, buscou-se caracterizar o mercado potencialmente promissor da agricultura irrigada como grande consumidor da água de reuso, em função de este setor possuir elevado consumo de água no país e no mundo; segundo ANA (2020a), a maior retirada de água nos mananciais brasileiros $(49,8 \%)$ se destina exatamente ao setor irrigação. A etapa c destinase a estabelecer o modelo de negócio a ser criado entre o fornecedor do efluente tratado e o consumidor, de forma a estabelecer uma sinergia entre os setores de saneamento e agrícola, com benefícios para a gestão dos recursos hídricos.

Importante destacar que essa integração entre os dados ( $\mathrm{AE}$ e $\mathrm{Al}$ ) e entre os setores (saneamento e agrícola), deve contemplar ações de reuso de água no Manual Operativo (MOP) de um plano de recursos hídricos de bacia hidrográfica. O MOP constitui um plano operacional que estabelece, para um conjunto de ações prioritárias propostas, o roteiro básico para a sua implementação prática durante os primeiros anos de horizonte de planejamento (SOARES et al., 2019). Assim, em um curto prazo, são definidos os responsáveis, os procedimentos necessários, os pré-requisitos e os resultados intermediários e finais esperados de cada uma dessas ações. Nesse sentido, o MOP tem por objetivo servir como um guia para o comitê da bacia e os órgãos gestores de recursos hídricos organizarem suas atuações de modo integrado e eficiente, promovendo a concretização dos programas e ações prioritárias do plano. Ao longo do horizonte do Plano, o MOP deve ser atualizado a cada ciclo de implementação.

As ações práticas da metodologia proposta, que envolvem o cotejo dos resultados do $A E$ e do Al, no contexto da discussão de ações para a viabilização do reuso regional, são exemplificadas para o PIRH-Grande e para o PRH-PPA. O primeiro, integrado por apresentar interação com os comitês dos rios afluentes, possui como uma de suas ações, a elaboração de estudo para identificar municípios e selecionar alternativas para reduzir os lançamentos de esgotos tratados em corpos receptores com pequena capacidade de assimilação das cargas remanescentes. O segundo, situado no Semiárido e elaborado durante a mais recente crise hídrica da região 
Nordeste, tem como foco apresentar soluções alternativas de abastecimento hídrico, visto as suas condições inerentes de baixos índices de precipitação aliados aos altos índices de evapotranspiração, tendo como consequência, rios intermitentes com sérias dificuldades relacionadas ao recebimento de efluentes, mesmo que tratados.

Na Figura 2, é possível observar o fluxograma do detalhamento da metodologia proposta (PARBH) que busca facilitar as ações de priorização da adoção da prática de reuso de água, no âmbito do planejamento de ações de recursos hídricos, em duas situações distintas: i) como alternativa para minimização de impactos de lançamento de efluentes tratados em rios com baixa capacidade de assimilação, e ii) como alternativa de abastecimento em regiões com cenários de escassez hídrica.

Importante destacar, por fim, que o AE (ANA, 2017b) e o Al (ANA, 2017c), bem como os dois planos de bacia coordenados pela ANA (ANA, 2018a; ANA, 2018b), foram realizados de forma independente, praticamente no mesmo período e sem objetivo específico em priorizar reuso de água no Brasil. No entanto, cada um deles possui contribuições a essa priorização, a partir da base técnica de planejamento. A metodologia PARBH busca, justamente, organizar essas diferentes abordagens e aspectos técnicos em uma sequência lógica, para que possa ser empregada como referência para futuras ações.

Figura 2: Fluxograma do detalhamento da metodologia PARBH

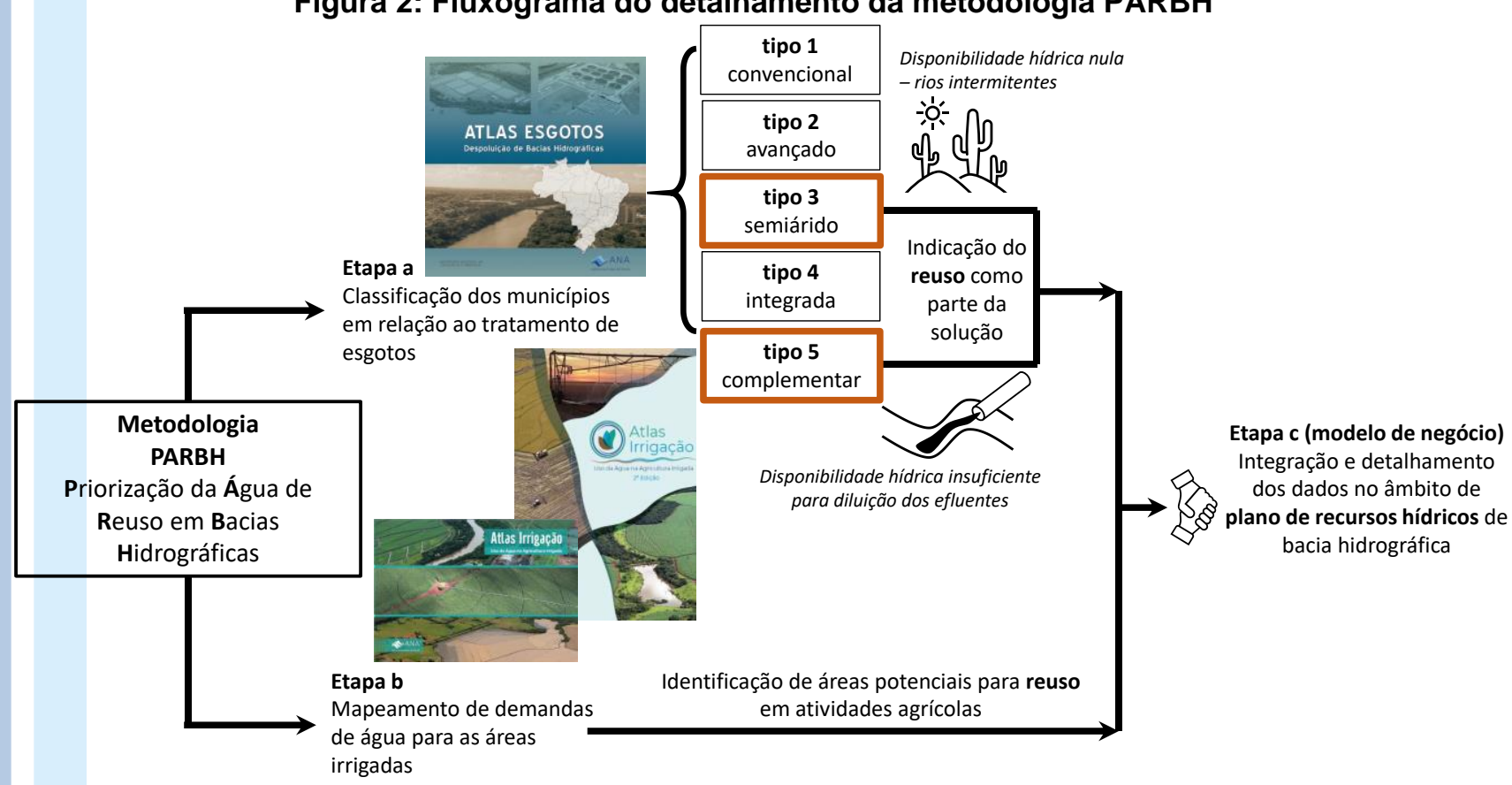

Fonte: Elaborado pelos autores.

\section{RESULTADOS E DISCUSSÃO}

De maneira análoga à metodologia, os resultados de aplicação da PARBH serão apresentados em decorrência das etapas a, b e c. Destaca-se, novamente, que se objetiva com esse modelo utilizar as informações de planejamento de recursos hídricos para subsidiar a estratégia de reuso da água na política de saneamento, como parte integrante dos esforços pra universalização do tratamento de esgotos, e na política de irrigação, como fonte hídrica complementar.
Etapa a - Classificação dos municípios em relação ao tratamento de esgotos $(A E)$

No $A E$ (ANA, 2017b), a modelagem de qualidade de água, considerando o lançamento de efluentes sanitários de todas as cidades do país e utilizando a bacia hidrográfica como unidade de análise, forneceu subsídios para a definição das eficiências requeridas, com base nos limites das classes de enquadramento estabelecidos pela Resolução CONAMA no 357/2005 (BRASIL, 2005). Determinou-se, então, a remoção de Demanda Bioquímica de Oxigênio (DBO) necessária para 
cada Estação de Tratamento de Esgoto (ETE) existente ou prevista, organizadas em duas situações: i) por processos convencionais, considerando-se 60 a $80 \%$ de eficiência; ou ii) por processos avançados com eficiência acima de $80 \%$. Não foram consideradas as unidades de tratamento com eficiências inferiores a $60 \%$, mesmo quando o corpo receptor apresentava elevada disponibilidade hídrica, embora essa flexibilização seja prevista na Resolução CONAMA no 430/2011 (BRASIL, 2011).

Os resultados da modelagem para $\mathrm{DBO}$, que consideraram o efeito acumulado das cargas de esgoto provenientes de montante, foram confrontados com a solução requerida em cada cidade quando analisada individualmente, sem influência dos demais lançamentos. Quando identificadas divergências entre os resultados do modelo e da análise individual de modo a exigir aumento da eficiência requerida, os municípios foram caracterizados pela necessidade de definição conjunta das soluções. Nos casos cuja máxima eficiência de remoção de carga orgânica não foi suficiente para atender às limitações legais, os municípios foram caracterizados pela necessidade de soluções complementares, como a disposição no solo ou reuso do efluente. Parte significativa dos municípios do Semiárido brasileiro encontram-se nessa situação, tendo em vista a condição de intermitência de vazão em grande parte dos corpos receptores. Por serem considerados como casos extremos da necessidade de soluções complementares, esse grupo de municípios foi caracterizado separadamente no Atlas Esgotos.

No Quadro 1, observam-se os tipos de solução para o tratamento e destinação final dos efluentes, sugeridas por ANA (2017b) organizadas para cada município do Brasil, além de fluxogramas e tecnologias para alcance dos desempenhos desejados em cada um dos tipos.

Observa-se que 0 reuso de água é claramente adotado pelo AE (ANA, 2017b) como solução possível nos tipos 3 e 5 , em que, respectivamente, consideram-se a escassez hídrica e a incapacidade de recebimento de cargas orgânicas adicionais nos corpos hídricos. Apesar de as categorias destacadas em relação ao desempenho de remoção de carga orgânica e/ou organismos patogênicos, Tsagarakis et al. (2012) sugerem que o reuso de água pode ser adotado com efluentes de diferentes níveis de tratamento, até mesmo o primário. Tzanakakis et al. (2011) indicam que o nível de tratamento primário, com eficiência de remoção de carga orgânica e de organismos patogênicos da ordem de $30-40 \%$, pode ser usado para irrigação de florestas e parques, considerando todas as medidas de segurança adotadas. Já os efluentes secundários podem ser adotados para a irrigação de culturas arbóreas onde não há contato direto com as culturas (PARANYCHIANAKIS et al., 2006), enquanto os efluentes terciários podem ser adotados para todos os tipos de cultura (MARIN et al., 2017; POON et al., 2006).

No entanto, o documento regulador da prática de reuso no Brasil (INTERÁGUAS, 2018), apesar de não mandatório, indica tecnologias de tratamento compostas por desinfecção direta ou desinfecção em duplo estágio para tipos de reuso restrito ou irrestrito, respectivamente. De acordo com Araujo (2019), tecnologias de desinfecção em duplo estágio adotam unidades de filtração terciária para redução de turbidez anteriormente à desinfecção, para garantia de melhores desempenhos de remoção/inativação de organismos patogênicos.

A Figura 3 apresenta um mapa do Brasil, com indicação das soluções de tratamento e disposição final de esgotos descritas no Quadro 1 (Tipos 1 a 5), classificadas no contexto dos municípios brasileiros. Observam-se ainda na mesma figura, duas representações gráficas que indicam uma relação entre os tipos de solução distribuídas por município (esquerda) e uma relação entre os tipos de solução por população projetada para 2035 (direita).

De maneira geral, a solução convencional (Tipo 1) é abordada por quase 3 mil dos 5570 municípios brasileiros, representando $24 \%$ da população projetada para 2035. As demais soluções juntas (Tipos 2, 3, 4 e 5), que de maneira direta ou indireta indicam possibilidade de reuso de água para atendimentos de diferentes objetivos, abordam 2601 municípios, representando $76 \%$ da população projetada para 2035. A solução do Tipo 3, que aborda diretamente o reuso de água como fonte alternativa para fins de escassez hídrica alcança 470 municípios do Semiárido ( $5 \%$ da população), enquanto a solução do Tipo 5, que indica o reuso de água para casos de incapacidade do corpo hídrico de recebimento de carga orgânica remanescente, representa 524 municípios (22\% da população) (ANA, 2017b). 
Quadro 1: Tipos de solução para tratamento e destinação final dos efluentes com respectivas tecnologias e fluxogramas de tratamento associados ao alcance de desempenho desejado.

\begin{tabular}{|c|c|c|}
\hline Tipo & Solução & Tecnologias/Fluxogramas \\
\hline $\begin{array}{l}1 \\
\text { Tratamento } \\
\text { convencional }\end{array}$ & $\begin{array}{l}\text { Principal corpo receptor possui } \\
\text { capacidade hídrica suficiente para diluir } \\
\text { os esgotos, mantendo-se as } \\
\text { concentrações de DBO dentro dos limites } \\
\text { para a classe } 2 \text { (BRASIL, 2005) com } \\
\text { desempenho de remoção de DBO entre } \\
60 \text { a } 80 \% \text {. }\end{array}$ & $\begin{array}{l}\text { Os reatores UASB (upflow anaerobic sludge } \\
\text { blanket) que atualmente representam a maior } \\
\text { vazão de efluente trado no Brasil (ANA, 2020b), } \\
\text { alcançam eficiências de remoção de DBO da } \\
\text { ordem de } 60 \text { a } 70 \% \text { (CHERNICHARO, 2016). } \\
\text { Os fluxogramas compostos por lagoas de } \\
\text { estabilização alcançam desempenhos em } \\
\text { torno de } 80 \% \text { (SPERLING, 2011). }\end{array}$ \\
\hline $\begin{array}{l}2 \\
\text { Tratamento } \\
\text { avançado }\end{array}$ & $\begin{array}{l}\text { Principal corpo receptor requer } \\
\text { tratamento com elevada remoção de DBO } \\
\text { (desempenho superior a } 80 \% \text { ) para se } \\
\text { enquadrar nos requisitos da classe } 2 \\
\text { (BRASIL, 2005). Essa situação ocorre em } \\
\text { municípios com corpos receptores com } \\
\text { baixa capacidade de diluição, nos quais a } \\
\text { solução de ampliação do desempenho é } \\
\text { suficiente. }\end{array}$ & $\begin{array}{l}\text { Os fluxogramas de tratamento de esgotos com } \\
\text { eficiência de remoção de DBO acima de } 80 \% \text {, } \\
\text { são considerados de nível secundário, de } \\
\text { acordo com Santos e Jordão (2021). } \\
\text { Tecnologias de biomassa suspensa (lodo } \\
\text { ativado e variantes) e de biomassa aderida } \\
\text { (filtros), bem operados, em geral, alcançam } \\
\text { desempenhos dessa ordem (SANTOS et al., } \\
\text { 2020). }\end{array}$ \\
\hline $\begin{array}{l}3 \\
\text { Semiárido }\end{array}$ & $\begin{array}{l}\text { Principal corpo receptor é intermitente ou } \\
\text { efêmero e está localizado no Semiárido } \\
\text { brasileiro. Além dos requisitos de } \\
\text { remoção de DBO, é importante considerar } \\
\text { a possibilidade de reuso do efluente } \\
\text { tratado e/ou priorizar processos de } \\
\text { tratamento que resultem em elevada } \\
\text { remoção de microrganismos patogênicos. }\end{array}$ & $\begin{array}{l}\text { Os processos de desinfecção, tais como } \\
\text { radiação UV, cloração e ozonização alcançam } \\
\text { elevadas eficiências de redução de organismos } \\
\text { patogênicos (SANTOS e JORDÃO, 2021). As } \\
\text { lagoas de maturação, muito marcantes no } \\
\text { Brasil (ANA, 2017b) desinfetam efluentes por } \\
\text { radiação UV natural, predação, sedimentação } \\
\text { e competição (SPERLING, 2011). Segundo } \\
\text { Lima et al., (2020), somente } 7 \% \text { dos esgotos } \\
\text { tratados no Brasil passam por algum tipo de } \\
\text { desinfecção, em geral lagoas de maturação. }\end{array}$ \\
\hline $\begin{array}{l}4 \\
\text { Conjunta }\end{array}$ & $\begin{array}{l}\text { Principal corpo receptor é impactado por } \\
\text { lançamentos de efluentes a montante, } \\
\text { exaurindo a sua capacidade de } \\
\text { assimilação de carga orgânica e } \\
\text { inviabilizando o lançamento de efluentes } \\
\text { a jusante. Os níveis de tratamento a } \\
\text { serem adotados em cada município } \\
\text { requerem uma discussão mais ampla, } \\
\text { sendo conveniente um acordo entre os } \\
\text { municípios de modo a alcançar solução } \\
\text { conjunta considerando capacidades } \\
\text { institucionais e financeiras. }\end{array}$ & $\begin{array}{l}\text { Neste caso, tecnologias mais avançadas como } \\
\text { os reatores biológicos com membranas, lodo } \\
\text { aeróbio granular, reatores biológicos de leito } \\
\text { móvel (moving bed biofilme reactor), entre } \\
\text { outros, alcançam melhores desempenhos e } \\
\text { apresentam efluentes com baixas } \\
\text { concentrações de matéria orgânica, sólidos e } \\
\text { nutrientes (SANTOS e JORDÃO, 2021). Os } \\
\text { reatores com membranas ainda reduzem } \\
\text { significativamente as densidades de } \\
\text { microrganismos patogênicos, a depender da } \\
\text { sua porosidade. }\end{array}$ \\
\hline $\begin{array}{l}5 \\
\text { Complementar }\end{array}$ & $\begin{array}{l}\text { Principal corpo receptor não possui } \\
\text { capacidade de diluição devido à baixa } \\
\text { relação entre a disponibilidade hídrica e a } \\
\text { carga orgânica lançada. Acontece } \\
\text { normalmente com os municípios } \\
\text { localizados em cabeceiras de rios. É } \\
\text { necessário buscar soluções adicionais: } \\
\text { escolha de novo corpo receptor, } \\
\text { disposição do efluente no solo, o reuso } \\
\text { do efluente tratado, entre outras. }\end{array}$ & $\begin{array}{l}\text { A disposição no solo pode ser alcançada em } \\
\text { diferentes situações como nos casos dos } \\
\text { sumidouros e das rampas de } \\
\text { filtração/infiltração (ABNT, 1997) e tecnologias } \\
\text { de terras úmidas artificiais (SPERLING, 2011). }\end{array}$ \\
\hline
\end{tabular}


Figura 3: Mapa do Brasil com indicações das soluções de tratamento e disposição final do esgoto tratado, com representações gráficas das soluções por municípios (esquerda) e por população projetada em 2035 (direita)

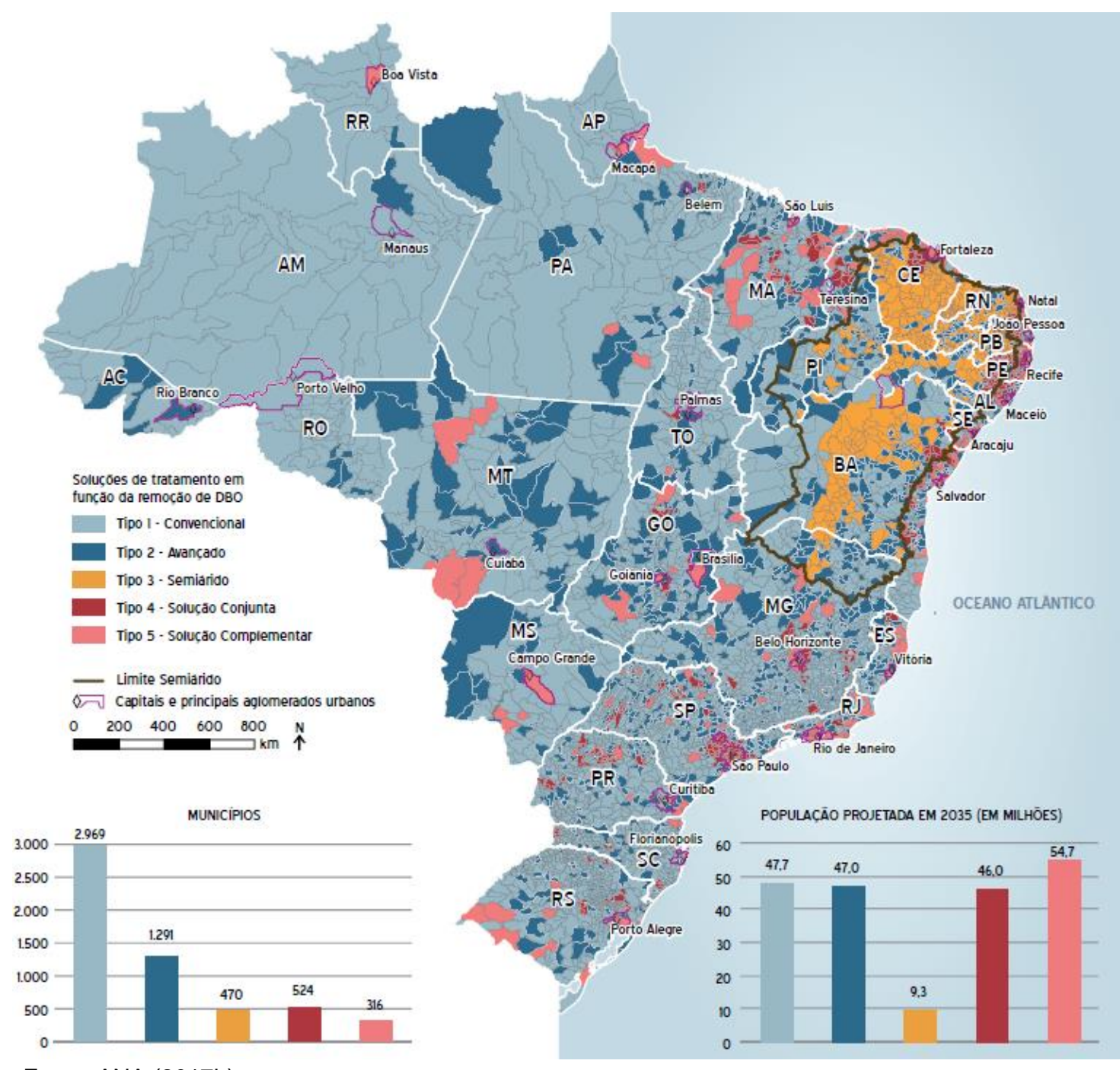

Fonte: ANA (2017b).

De forma explícita nas tipologias 3 e 5, mas também como estratégia para as soluções previstas nas tipologias 2 e 4 , o reuso deve ser considerado como parte integrante da concepção da melhor alternativa para o tratamento de esgotos e destinação final dos efluentes sanitários tratados. Nesse contexto, importante ter claro as potencialidades do reuso, particularmente no voltado para atividades agrícolas, visto que aumenta a oferta de água, pode representar uma fonte de fertilizante e geralmente apresenta menor custo de tratamento do que a água potável.

Etapa b - Mapeamento das demandas de água para as áreas irrigadas (Al)

Os dados publicados na segunda edição do Al (ANA, 2021) possibilitam traçar um panorama completo do mapeamento de áreas irrigadas no Brasil, bem como do uso da água pela agricultura irrigada. Atualmente, o Brasil totaliza 8,2 milhões de hectares equipados para irrigação, sendo $64,5 \%$ (5,3 Mha) com água de mananciais e 35,5\% (2,9 Mha) com fertirrigação com água de reuso. No segundo caso, o reuso é praticado essencialmente com efluente direto do processamento da cana de açúcar.

A estratégia de mapeamento, coordenada pela Agência Nacional de Águas e Saneamento Básico (ANA), e desenvolvida com vários parceiros institucionais, foi organizada por tipologias de cultura e métodos de irrigação (arroz; cana-de-açúcar; café; culturas anuais em pivôs centrais e demais culturas e sistemas) em base técnica única. Essa base também conta com estimativa de uso da água pela agricultura irrigada, 
que soma $965 \mathrm{~m}^{3} / \mathrm{s}$ para um cenário de clima médio em 2019. Até 2040, estima-se a incorporação de 4,2 milhões de hectares irrigados (+76\%), com um impacto menor sobre a expansão do uso da água (+66\%) devido ao emprego de métodos cada vez mais eficientes (ANA, 2021).
Na Figura 4 observa-se o mapa do Brasil com destaque para as tipologias de culturas e métodos de irrigação por município brasileiro e a representação gráfica das áreas irrigadas para cada tipologia, bem como suas ocupações em relação à área total irrigada.

\section{Figura 4: Mapa do Brasil com as tipologias de irrigação por município (a) e representação gráfica das áreas irrigadas para cada tipologia em relação à área total irrigada (b).}

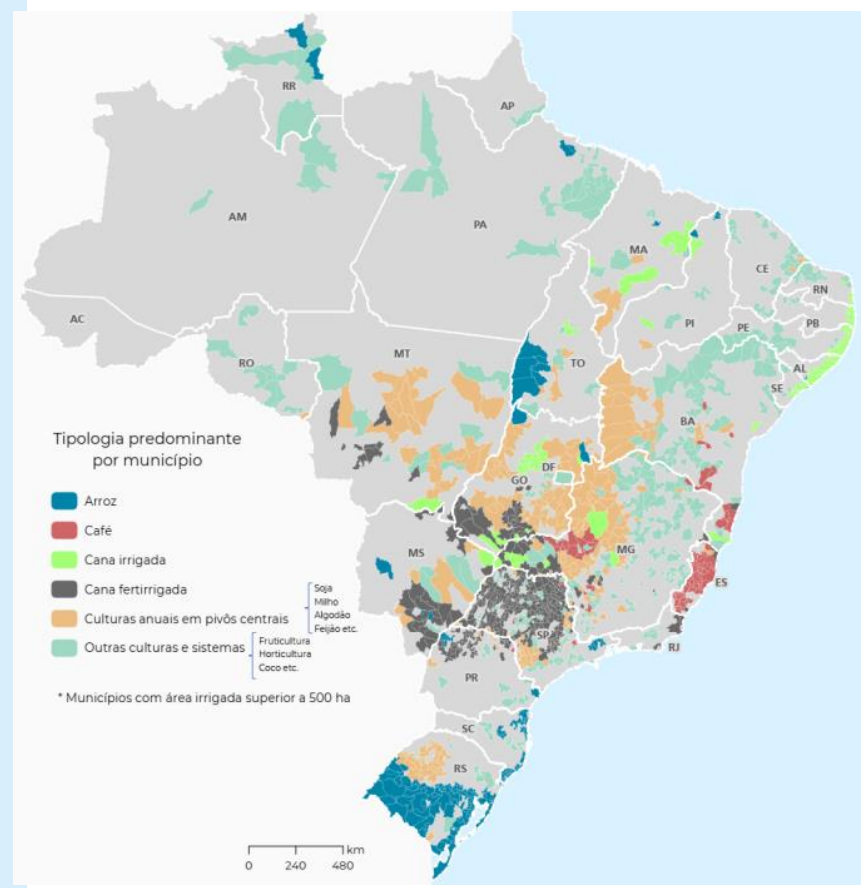

(a)

Fonte: ANA (2021).

A agricultura irrigada pode ser uma importante aliada para diminuição ou mitigação da poluição hídrica das cidades. $O$ setor sucroenergético, por exemplo, realiza o maior reuso agroindustrial do Brasil com a fertirrigação da cana-de-açúcar a partir dos efluentes gerados no processamento da cana (ANA, 2021). De acordo com Lima et al. (2020), todo o esgoto tratado no Brasil representa $9 \%$ da demanda de água para irrigação no país, sendo que em duas regiões hidrográficas brasileiras (Paraná e Paraguai), essa relação é superior a 40\%; em 8 das 12 regiões hidrográficas, esse potencial é inferior a 5\%. No caso da bacia do rio Grande, Santos et al. (2019) observaram que a vazão de água de reuso poderia corresponder à mais de $25 \%$ da demanda média para irrigação no cenário 2035. Para esse mesmo horizonte, Araujo et al. (2020) indicam que a oferta de água de reuso
Área equipada para irrigação no Brasil - 2019

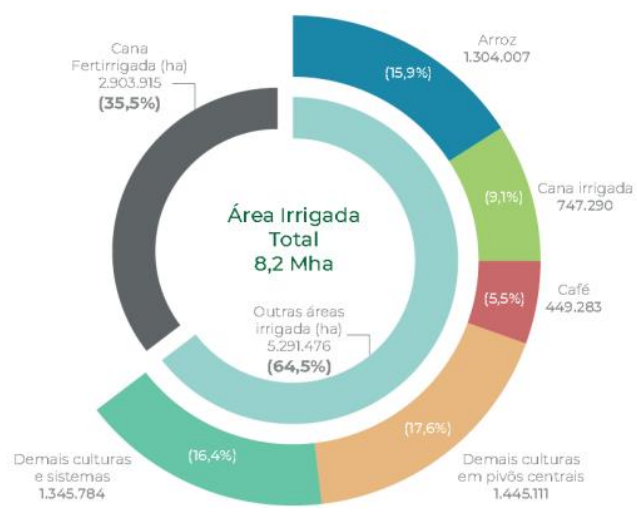

(b) poderá representar $8 \%$, da demanda de água para o uso na irrigação na bacia Piancó-piranhas-Açu, sendo que a implantação dessa prática poderá reduzir a pressão hídrica no abastecimento de água em até metade de sua demanda.

Importante salientar que apesar do bom potencial de reuso de água para o setor agrícola no Brasil, e nas bacias do Grande e do PiancóPiranhas-Açu, devem ser avaliadas questões práticas como custo, transporte, política de cobrança, fiscalização e outros, de forma a garantir a sustentabilidade das ações. Esse conjunto de medidas deve integrar o "modelo de negócio" da prática do reuso de cada bacia hidrográfica, devendo ser incluí-las como ações nos respectivos planos de bacia.

Etapa c - Integração dos dados (modelo de negócio) 
A integração de dados entre oferta de efluente (etapa a) e demanda de água (etapa b) que perfazem uma ferramenta de avaliação de potencial de reuso de água a partir de efluente tratado é um importante fator de planejamento de recursos hídricos e saneamento em integração com o setor de irrigação.

No entanto, mesmo o potencial se apresentado médio-alto em algumas regiões, há que se considerar dois fatores relevantes: i) nas outras regiões, o principal motivo para o potencial ser baixo está relacionado aos baixos índices de cobertura com serviço de esgotamento sanitário; ii) mesmo o potencial instalado garantido efluentes tratados em fluxogramas que envolvem tecnologias de tratamento de esgotos com desempenho teórico de remoção de DBO entre 60 e $80 \%$ (primário avançado) e acima de $80 \%$ (secundário), há que se levar em consideração a qualidade operacional. Segundo Moraes et al. (2020), o eixo concepção-projeto-implantaçãooperação, nas condições de infraestruturas de saneamento no Brasil não é bem estruturado, levando a processos operacionais de ETE insatisfatórios.

De forma a ilustrar a metodologia apresentada, nessa etapa, abordam-se os estudos de caso de bacias hidrográficas com planos de recursos hídricos, que nomeadamente se encaixam às tipologias 3 e 5 apresentadas por ANA (2017b) como forma de solução para destinação final de efluentes tratados: $\mathrm{PIRH}-$ Grande e PRH-PPA.

\section{- Caso da bacia do Rio Grande}

A bacia hidrográfica do rio Grande é caracterizada por elevada taxa de urbanização e numerosa população, sendo compartilhada pelos estados de São Paulo e Minas Gerais. Abrange um território de $143.255 \mathrm{~km}^{2}$, em que se inserem, total ou parcialmente, 393 municípios e concentra cerca de 5\% do PIB nacional (LIMA et al., 2019; ANA, 2015). A elaboração do seu plano de bacia (ANA, 2018a) se deu entre os anos de 2015 e 2017 e contou com a participação ativa do comitê federal e dos comitês estaduais das 14 bacias afluentes ao rio Grande, seis delas situadas na vertente paulista da bacia e oito na vertente mineira, buscando-se alinhamento de expectativas e de conteúdo.

No PIRH-Grande foram desenvolvidas simulações de propagação de cargas poluentes originadas de áreas urbanas ao longo dos corpos hídricos com apoio de modelagem de qualidade da água, confirmando a ocorrência de diversos trechos que ultrapassam os limites da classe 4, identificados no AE como tipologia 5 (solução complementar). Isso decorre da elevada carga poluidora de cidades de grande porte associada à baixa capacidade de diluição de poluentes dos corpos hídricos receptores desse efluentes, mesmo onde o tratamento promove altos níveis de remoção de cargas orgânicas.

Para que esses corpos hídricos passem a apresentar melhor qualidade, compatíveis com níveis de classe 3 ou de qualidade superior, o plano indicou a necessidade de estudar alternativas à disposição final atual dos esgotos tratados, uma vez que número significativo de corpos receptores da região apresenta pequena capacidade de assimilação das cargas orgânicas remanescentes. Esse apontamento culminou em uma ação específica contida no MOP. Trata-se da ação 4.10, abordada no Programa 11, com o seguinte escopo "elaborar estudo para identificar municípios e selecionar alternativas para reduzir os lançamentos de esgotos tratados em corpos receptores com pequena capacidade de assimilação das cargas remanescentes".

Para a operacionalização desse estudo, optou-se por 5 (cinco) municípios na bacia (Catanduva, Leme, Sertãozinho, Ribeirão Preto e Mogi Mirim), considerando aspectos como o porte populacional, os índices de cobertura de esgotamento sanitário, as eficiências de remoção de carga orgânica do tratamento existente, a qualidade da água no corpo receptor e a proximidade a instalações de usinas sucroalcooleiras (cultura predominante na região), caracterizando uma grande oportunidade para avaliação da solução alternativa de reuso agrícola. O estudo objetiva, em síntese, definir o conjunto de usuários potenciais e suas disposições em utilizar a água de reuso e fazer uma avaliação da viabilidade econômica e financeira dos projetos.

\section{- Caso da bacia do rio Piancó-Piranhas-Açu}

A bacia hidrográfica do rio Piancó-PiranhasAçu é a maior da região hidrográfica Atlântico Nordeste Oriental, com área total de $43.683 \mathrm{~km}^{2}$. Seu território divide-se entre os estados da Paraíba (60\%) e Rio Grande do Norte (40\%) e está totalmente inserida em região de clima semiárido. Em um contexto de baixa disponibilidade hídrica e ocorrência de rios intermitentes, associados à elevada demanda de água, principalmente para 
abastecimento humano e irrigação, e à poluição decorrente da precária infraestrutura de saneamento das cidades, a gestão da água na bacia torna-se ainda mais desafiadora. Segundo Lima et al. (2020), na região hidrográfica Atlântico Nordeste Oriental a vazão total de esgoto tratado representa $9 \%$ da demanda de água para irrigação.

No que se refere a qualidade da água, as condições nos reservatórios da bacia dos rios Piancó-Piranhas-Açu, com frequentes inconformidades na concentração de fósforo, constituem um indício generalizado de estado de eutrofização relevante e de que a capacidade de suporte a cargas de fósforo já está comprometida frente a expectativa desejável de manutenção de padrões de qualidade compatíveis com 0 abastecimento para consumo humano. Essa situação atual, além da limitada capacidade de assimilação de cargas poluidoras, em função das características dos açudes e da intermitência dos rios, indica a necessidade de investimentos em esgotamento sanitário e de busca de alternativas para o lançamento de efluentes, tais como o reuso (tipologia 3 indicada no AE).

Nesse contexto, o PRH Piancó-Piranhas-Açu (ANA, 2018b) possui diretriz para a outorga de lançamento de efluentes, que considera que os rios intermitentes, açudes e trechos perenizados não deverão, a longo prazo, receber aporte de esgotos, devendo ser encaminhados para reuso ou aplicados no solo. Exceção poderá ser feita desde que a solução apresentada, comprovadamente, não comprometa a capacidade de suporte dos reservatórios e a compatibilidade da qualidade da água para os demais usos existentes nos corpos receptores. Além disso, o plano recomenda ao prestador de serviço de saneamento que invista em projetos e parcerias de reuso das águas residuárias, principalmente na agricultura irrigada; e ao setor governamental, que elabore estudos e projetos considerando as soluções de saneamento compatíveis com aquelas definidas no $\mathrm{AE}$, coerentes com as condições regionais e a realidade operacional dos prestadores de serviços e, consequentemente, com o emprego de tecnologias apropriadas, incorporando diretrizes técnicas referentes ao reuso de água.

O plano de bacia apresenta suas intervenções organizadas em três componentes: (i) gestão de recursos hídricos, constituído por programas que envolvem ações não estruturais voltadas para gestão e uso sustentável dos recursos hídricos; (ii) estudos de apoio à gestão, constituído por programas voltados para ampliação do conhecimento sobre os recursos hídricos para subsidiar a melhoria da gestão; (iii) estudos e projetos de medidas estruturantes, constituído por programas voltados para fornecimento de subsídios técnicos (estudos e projetos) para ações estruturais necessárias para melhoria da infraestrutura de oferta de água e de saneamento nas zonas urbana e rural da bacia. $\mathrm{O}$ componente 1 inclui ação de implantação de projetos-piloto de reuso de água para agricultura, cujos projetos para 4 cidades (Itaporanga, Jucurutu, São Fernando e Serra Negra) da bacia foram selecionados.

Assim como no caso da bacia do Grande, embora o contexto seja bastante distinto, a estratégia do desenvolvimento de estudos específicos em algumas cidades se mostra necessária para a definição do modelo de negócio que viabilize o reuso na região.

\section{DESAFIOS}

Embora a aplicabilidade da prática do reuso de água seja certa e a sua necessidade seja evidente, muitos desafios ainda devem ser transpostos de forma a torná-la uma ação sistematizada e institucionalizada no país. Inicialmente, destaca-se a insatisfatória qualidade dos serviços de esgotamento sanitário prestados no Brasil. A prática de reuso de água depende essencialmente da disponibilidade de esgoto tratado e em um nível adequado para a sua aplicação em diversos usos. Entretanto, conforme já destacado, o Brasil apresenta baixos índices de cobertura com tratamento de esgotos (ANA, 2017b), além de insatisfatória qualidade operacional dos sistemas implantados, em muitos casos (MORAES et al., 2020).

Outro ponto que merece destaque, é a falta de regulamentação adequada, a nível federal, que dê respaldo e segurança jurídica às ações de reuso, bem como permitam uma prática segura e responsável. De acordo com Santos et al. (2020), no Brasil, o documento nacional regulador vigente, o Interáguas (2018), é apenas norteador e não tem força legal. No entanto, o documento apresenta padrões de qualidade de água para diferentes tipos de reuso, além de outras diretrizes como direcionamento para o licenciamento da prática, indicação da necessidade de um seguro contra incidentes, abordagem da análise de risco microbiológico e sugestões de tecnologias 
apropriadas para alcance das diferentes qualidades desejada. Santos et al. (2020) destacam o avanço do país em relação à publicação de documentos reguladores mandatórios de reuso de água em níveis subfederais (estados da Bahia, do Ceará, de São Paulo, de Minas Gerais e do Rio Grande do Sul), com definição de padrões de qualidade de água para diferentes fins de reuso. Porém, os mesmos autores apontam para a falta de coerência entre eles, em se tratando de padrões muito ou pouco restritivos para os mesmos tipos de reuso nos diferentes documentos.

Ainda, a cultura histórica de falsa abundância de água, que prejudica a conservação e o uso racional de água, além dos entraves burocráticos para o desenvolvimento das ações de saneamento ambiental e da falta de estudos técnico-científicos e econômicos de viabilidade de implantação dos projetos de reuso de água, levam à morosidade das ações e a insegurança, por parte de potenciais fornecedores e usuários de água de reuso, no sentido de sistematização da prática no Brasil.

Por fim, um desafio que merece destaque diante dos demais, é lidar com a rejeição psicológica e natural em relação ao reuso de água. De acordo com Mukherjee e Jensen (2020), muitos projetos de reuso podem não sair do papel, em função dessa rejeição, conhecida no meio científico como Factor Yuck (Fator "eca" em português). Para vencer esse desafio, alguns fatores são elencados e apresentam abordagem significativa no Brasil:

- Relação de confiança entre produtores e possíveis usuários e consumidores da água de reuso. Em geral, as relações entre as prestadoras de serviços de saneamento (tanto por administração direta como indireta, além de empresas públicas ou privadas) e os seus consumidores e usuários são desgastadas ao longo dos anos. Nesse sentido, é de grande relevância que as empresas invistam no desenvolvimento da imagem e na solidificação dessa relação no contexto da aplicação de empreendimentos de reuso. Uma relação de confiança deve ser conquistada e construída em pilares sólidos para o fortalecimento desse relacionamento.

- Transparência das ações relacionadas à prestação de serviços dessa natureza. Em geral, há uma enorme dificuldade de acesso aos dados qualitativos dos serviços prestados pelas companhias de água e esgoto aos seus consumidores. $\mathrm{O}$ elo de confiança entre potenciais produtores e consumidores de água de reuso passa pela transparência das ações. Nesse sentido, o desenvolvimento de projetos-piloto, anteriormente à condução de projetos em escala real, com a intenção de disponibilização de dados, de permissão de visitação e de publicação técnico-científicas dos resultados pode ser uma das principais ações de garantia do sucesso dos empreendimentos de reuso de água, em relação ao quesito "rejeição".

- Adoção de identidade visual para as ações de reuso de água. Conforme destacado por Santos et al. (2020), os estados de Minas Gerais e São Paulo deram importantes passos quando definiram, em seus documentos reguladores, identidade visual para veículos e empreendimentos relacionados ao reuso de água. Essa ação é fundamental para uma construção de conhecimento por parte da sociedade civil, que passa a aceitar melhor as ações inicialmente desconhecidas.

- Participação da sociedade nas decisões. Embora seja esperada uma gestão de saneamento participativa, que envolva a sociedade civil além da comunidade técnica nas decisões de projetos de infraestrutura de saneamento e recursos hídricos, muitas vezes os caminhos não são exatamente assim. Em geral, por falta de conhecimento e/ou por falta de interesse, as ações acabam sendo tomadas à revelia do posicionamento e do conhecimento da sociedade civil, dificultando seu engajamento e aceitação.

\section{CONCLUSÕES}

O presente artigo apresentou uma metodologia de priorização da adoção de medidas de reuso de água para irrigação, no âmbito dos planos de recursos hídricos das bacias hidrográficas, denominada PARBH. Essa abordagem, que utiliza como base técnica os resultados do Atlas Esgotos e Atlas Irrigação (AE e $\mathrm{Al}$ ), estudos de planejamento coordenados pela ANA, privilegia dois cenários: i) áreas que contemplam corpos d'água receptores incapazes de recebimento de efluentes, mesmo que tratados, 
por apresentarem atualmente níveis elevados de poluição hídrica, e ii) áreas de escassez hídrica, como aquelas instaladas no contexto da região do Semiárido, que contam com rios intermitentes, baixos índices pluviométricos e altos índices de evapotranspiração. Esses dois aspectos foram abordados e exemplificados nos contextos dos planos da bacia hidrográfica do Grande e da bacia hidrográfica do Piancó-Piranhas-Açu, respectivamente.

No caso da bacia do rio Grande, cinco municípios foram priorizados, de acordo com resultados apresentados pela avaliação de condições propostas em estudo de modelagem de qualidade de água que abordaram diferentes cenários de lançamento de efluentes nos corpos hídricos da região. Os resultados da simulação demonstraram a incapacidade de assimilação das cargas orgânicas provenientes dos lançamentos, indicando o reuso de água como uma das alternativas para a disposição final. Conclui-se que neste cenário, os municípios podem ser escolhidos de acordo com os seguintes aspectos: porte populacional, índices de cobertura de esgotamento sanitário, eficiências de remoção de carga orgânica do tratamento existente, qualidade da água no corpo receptor, e proximidade a instalações de usinas sucroalcooleiras (cultura predominante na região).

No caso da bacia hidrográfica dos rios Piancó-Piranhas-Açu, com ampla presença de rios intermitentes, além de cenários de eutrofização dos açudes, o plano da bacia indica a proibição de lançamento de efluentes nos rios mais vulneráveis da região, que naturalmente leva à adoção de medidas de reuso de água tanto por parte das prestadoras de serviço como por parte dos governos regionais. Nos dois exemplos, fica evidente a necessidade de se detalhar o modelo de negócio do reuso da água na agricultura irrigada por meio de estudos específicos e conduzidos a partir da implementação dos respectivos planos de bacia.

Por fim, conclui-se que mesmo diante dos potenciais demostrados de aplicabilidade do reuso de água nas bacias hidrográficas de estudo, há grandes desafios a serem transpostos, de forma a tornarem a prática de reuso sistematizada e institucionalizada no Brasil. Destacam-se a necessidade de avanços em relação à universalização dos serviços de esgotamento sanitário, com operação adequada, segura e responsável para a produção de água de reuso com qualidades compatíveis aos usos pretendidos; regulamentação coerente, adequada e aplicada às condições e características brasileiras; e ferramentas de planejamento, gestão e educação de produtores e usuários de água de reuso, além da sociedade civil e todos os envolvidos com a prática, de forma a minimizar os efeitos da rejeição natural e psicológica.

\section{AGRADECIMENTOS}

Os estudos de caso analisados, que tratam de planos de recursos hídricos coordenados pela ANA, tiveram ampla participação em seu processo de elaboração, sendo fundamentais os colegiados responsáveis pelo acompanhamento e aprovação desses planos ( $\mathrm{CBH}$ Grande e $\mathrm{CBH}$ PiancóPiranhas-Açu), bem como os órgãos gestores de recursos hídricos dos seguintes estados: Minas Gerais, Paraíba, Rio Grande do Norte e São Paulo.

\section{REFERÊNCIAS}

ABNT. ASSOCIAÇÃO BRASILEIRA DE NORMAS TÉCNICAS. NBR 13969: Tanques sépticos - Unidades de tratamento complementar e disposição final dos efluentes líquidos - Projeto, construção e operação. Rio de Janeiro. 60p. 1997.

\section{ANA. AGÊNCIA NACIONAL DE ÁGUAS. Bacia Hidrográfica do Rio Grande Diagnóstico Preliminar - Abastecimento Urbano de Água. / Agência Nacional de Águas. Brasília: ANA, 2015.}

ANA. AGÊNCIA NACIONAL DE ÁGUAS. Conjuntura dos recursos hídricos no Brasil 2017: relatório pleno / Agência Nacional de Águas. Brasília: ANA, 2017a.

ANA. AGÊNCIA NACIONAL DE ÁGUAS. Atlas

esgotos: despoluição de bacias hidrográficas. Brasília, DF: ANA, 2017b.

ANA. AGÊNCIA NACIONAL DE ÁGUAS. Atlas

irrigação: uso da água na agricultura irrigada. Brasília, DF: ANA, 2017c.

\author{
ANA. AGÊNCIA NACIONAL DE ÁGUAS. Plano \\ Integrado de Recursos Hídricos da Bacia \\ Hidrográfica do Rio Grande - PIRH-Grande: resumo \\ executivo. Brasília, DF: ANA, 2018a.
}

\section{ANA. AGÊNCIA NACIONAL DE ÁGUAS. Plano de recursos hídricos da bacia hidrográfica do rio Piancó-Piranhas-Açu: resumo executivo. Brasília, DF: ANA, 2018b.}

ANA. AGÊNCIA NACIONAL DE ÁGUAS. ODS 6 no Brasil: visão da ANA sobre os indicadores. Brasília, DF: ANA, 2019a. 
ANA. AGÊNCIA NACIONAL DE ÁGUAS. Plano Nacional de Segurança Hídrica. Brasília, DF: ANA, 2019b.

ANA. AGÊNCIA NACIONAL DE ÁGUAS E SANEAMENTO BÁSICO. Conjuntura dos recursos hídricos no Brasil 2020: informe anual / Agência Nacional de Águas. Brasília: ANA, 2020a.

ANA. AGÊNCIA NACIONAL DE ÁGUAS. Atlas esgotos: atualização da base de dados de estações de tratamento de esgotos no Brasil. Brasília, DF: ANA, 2020b.

ANA. AGÊNCIA NACIONAL DE ÁGUAS E SANEAMENTO BÁSICO. Atlas Irrigação: uso da água na agricultura irrigada. Brasília, DF: ANA, 2021.

ANGELAKIS, A. N.; ASANO, T.; BAHRI, A.; JIMENEZ, B. E.; TCHOBANOGLOUS G. Water Reuse: From Ancient to Modern Times and the Future. Frontiers Environmental Science, v. 6, n. 26, 2018.

ARAUJO, B. M. Avaliação da aplicabilidade da filtração terciária para condicionamento de efluente secundário a desinfecção por radiação ultravioleta. Dissertação (Mestrado) - Universidade do Estado do Rio de Janeiro, Faculdade de Engenharia. 2019.

ARAUJO, B. M.; SANTOS, A. S. P. S; LIMA, M. A. M., SOARES, S. R. A; PERDIGÃO, C. A.; MELO, M. C. Avaliação do potencial de reuso de efluentes de ETE de áreas irrigadas da bacia hidrográfica PiancóPiranhas-Açu com vistas á universalização. Revista Augustus, v. 24, n. 49, p. 179-191, 2020.

BRASIL. Lei no 9.433, de 8 de janeiro de 1997. Institui a Política Nacional de Recursos Hídricos, cria o Sistema Nacional de Gerenciamento de Recursos Hídricos. Diário Oficial da União. Brasília, DF, 1997.

BRASIL. RESOLUÇÃO DO CONSELHO NACIONAL DO MEIO AMBIENTE (CONAMA) n³57/2005. Dispõe sobre a classificação dos corpos de água e diretrizes ambientais para o seu enquadramento. Diário Oficial da União, Brasília, 2005.

BRASIL. RESOLUÇÃO DO CONSELHO NACIONAL DO MEIO AMBIENTE (CONAMA) $n^{\circ} 430 / 2011$. Dispõe sobre as condições e padrões de lançamento de efluentes. Diário Oficial da União, Brasília, 2011.

CHERNICHARO, C.A.L. Reatores anaeróbios. 2. ed. Belo Horizonte. UFMG, 2016.

HESPANHOL, I. Um novo paradigma para a gestão de recursos hídricos. Estudos Avançados, São Paulo, v. 22, n. 63, p. 131-158, 2008.
HORTEGAL FILHA, M. S. R. et al. Aspectos agronômicos da mamoneira irrigada com efluentes tratados. Revista DAE, São Paulo, v. 66, n. 213, p. 20 35, 2018.

INTERÁGUAS - PROGRAMA DE DESENVOLVIMENTO DO SETOR ÁGUAS.

Elaboração de proposta de plano de ações para instituir uma política de reúso de efluente sanitário tratado no Brasil. Produto III - Critérios de qualidade de água. Brasília. 2018.

JONES, E.R.; VILET, M.T.; QADIR, M.; BIERKENS, M.F.P. Country-level and gridded estimates of wastewater production, collection, treatment and reuse. Earth System Science Data, v. 13, p. 237-254, 2021.

LAHNSTEINER, J.; VAN RENSBURG, P.; ESTERHUIZEN, J. Direct potable reuse - a feasible water management option. Water reuse and desalination, v. 8, n. 1, 2018.

LIMA, M.; ARAUJO, B. M.; SOARES, S. R. A.; SANTOS, A. S. P.; VIEIRA, J. M. P.; Water reuse potential for irrigation in Brazilian hydrographic regions. Water Supply, 2020.

MARIN, P. TAL, S., YERES, J. RINGSKOG, K. Water Management in Israel: Key Innovations and Lessons Learned for Water-Scarce Countries. World Bank, Washington, DC, 2017.

MORAES, D. L.; SANTOS, A. S. P.; BILA, D. M.; SILVA JÚNIOR, L. C. S.; ARAUJO, B. M. Análise comparativa de parâmetros hidráulicos para dimensionamento de tecnologias em Estações de Tratamento de Esgoto. Revista Internacional de Ciências, v. 10, p. 22-41, 2020.

MUKHERJEE, M.; JENSEN, O. A comparative analysis of the development of regulation and technology uptake in the US and Australia. Safety Science, v. 121, p. 514, 2020.

PARANYCHIANAKIS, N.V.; ANGELAKIS, A.N.; LEVERENZ, H.; TCHOBANOGLOUS, G. Treatment of wastewater with slow rate systems: A review of treatment processes and plant functions. Critical Reviews. Environmental Science and Technology, v. 36, n. 3, p. 187-259, 2006.

POON, J., KEEGAN, A., DEERE, D., DAVISON, A. AND MONIS, P. UV disinfection for class a water recycling. Water, v. 33, n. 6, p, 56-60, 2006.

SANTOS, A. S. P; LIMA, M. A. M.; RAMOS, L. T. A.; SOARES, S. R. A,; PEREIRA, C.B. Avaliação do potencial de reuso de efluente de ETE para o setor agrícola na bacia hidrográfica do Rio Grande. In: 39º 
Congresso Brasileiro de Engenharia Ambiental e Sanitária, Natal, 2019. Anais [...], Natal, RN, 2019.

SANTOS, A. S. P.; GONÇALVES, R. F.; MELO, M. C.; LIMA, M. A. M.; ARAUJO, B. M. Uma análise crítica sobre os padrões de qualidade de água de uso e de reúso no Brasil. Revista Sustinere, v. 8, n. 2, p. 437462, 2020.

SANTOS, A. S. P.; VIEIRA, J. M. P. Reúso De Água Para O Desenvolvimento Sustentável: Aspectos de regulamentação no Brasil e em Portugal. Revista Eletrônica de Gestão e Tecnologias Ambientais, v. 8, p. 50-68, 2020.

SANTOS, A. S. P.; JORDÃO, E. P. Sistemas de esgotamento sanitário. In: Engenharia e Meio Ambiente - Aspectos conceituais e práticos. $1^{\underline{a}} \mathrm{Ed}$., LTC. 2021.

SOARES, S. R. A.; ANDRADE, L. A. Z.; SILVA, M. A.; FERMNANDEZ, G. A. V.; MACHADO, E.G.B.; EVANGELISTA, R. M.; PESSOA, C. A. P. Planos de recursos hídricos em bacias hidrográficas interestaduais: casos do Paranapanema, PiancóPiranhas-Açu e Paraguai. In: Gestão de Bacias Hidrográficas e Sustentabilidade. Barueri, SP: Manole. 2019.

SPERLING, M. Introdução à qualidade das águas e ao tratamento de esgoto. 4. ed. Belo Horizonte. UFMG, 2011.
TSAGARAKIS, K.P.; MENEGAKI, A.N.; SIARAPI, K.; ZACHAROPOULOU, F. Safe alerts reduce willingness to visit park irrigated whit recycled water. Journal of risk research, v. 16, n. 2, 2012.

TZANAKAKIS, V.A.; PARANYCHIANAKIS, N.V.; LONDRA, P.A.; ANGELAKIS, A.N. Effluent application to the land: Changes in soil proprieties and treatment potential. Ecological Engineering, v. 37, n. 11, p. 1757- 1764, 2011.

UNITED NATIONS. Resolution adopted by the general assembly on 25 september 2015. [New York]: UN, 2015. Disponível em:

https://www.un.org/en/development/desa/population/mi gration/generalassembly/docs/globalcompact/A_RES_7 0_1_E.pdf. Acesso em: 10 de março de 2020.

UNITED NATIONS. Resolution adopted by the general assembly on 28 july 2010. [New York]: UN, 2010. Disponível em:

https://undocs.org/en/A/RES/64/292. Acesso em: 10 de março de 2020.

WATER EUROPE. A water smart society for a successful post COVID19 recovery plan. Bruxelas: WE, 2020. Disponível em: https://watereurope.eu/wpcontent/uploads/2020/04/A-Water-Smart-Society-for-apost-covid19-recovery-plan.pdf. Acesso em: 9 dez. de 2020. 